\title{
Unusual Initial Presentation of Celiac Disease in Children: Three Case Reports
}

\author{
Sevgi Buyukbese Sarsu ${ }^{*}$, Mustafa Demirci² \\ ${ }^{1}$ Department of Pediatric Surgery, Cengiz Gokcek Obstetrics and Children's Hospital, Gaziantep, Turkey \\ ${ }^{2}$ Department of Radiology, Cengiz Gokcek Obstetrics and Children's Hospital, Gaziantep, Turkey \\ Email:"sarsusevgi@yahoo.com.tr,drdemirci@hotmail.com
}

Received 30 January 2016; accepted 4 March 2016; published 9 March 2016

Copyright (C) 2016 by authors and Scientific Research Publishing Inc.

This work is licensed under the Creative Commons Attribution International License (CC BY).

http://creativecommons.org/licenses/by/4.0/

(c) (i) Open Access

\section{Abstract}

Background: The togetherness of invagination with celiac disease is an extremely rare condition especially in children. However, invagination may be the presenting symptom of celiac disease. Moreover, recurrent invaginations have been also reported in patients with celiac disease. Aim: To increase the awareness of clinicians about togetherness of these conditions. Case Presentation: Herein, we will discuss three children with diagnosis of celiac disease who presented with invagination and intestinal pseudo-obstruction. Conclusion: Children with pseudo-obstruction and invagination without an underlying etiology should be evaluated for the presence of celiac disease, especially if they have accompanying growth retardation or anemia and if they are at an unusual age for invagination. Further studies are warranted to elucidate the exact relationship of invagination with celiac disease.

\section{Keywords}

Celiac Disease, Invagination, Intestinal Pseudo-Obstruction, Children

\section{Introduction}

Invagination is one of the most common causes of gastrointestinal obstruction in children [1]. Though it is usually idiopathic, tumors, Meckel diverticula, viral infections [2], cystic fibrosis, Crohn disease and celiac disease (CD) may rarely cause invagination [1].

Celiac disease is an autoimmune enteropathy affecting genetically predisposed patients [3]. The typical symptoms of CD include growth retardation, abdominal distention and anemia. However, patients may present with atypical symptoms such as neurological symptoms, or invagination [3] [4]. The togetherness of invagination

\footnotetext{
${ }^{*}$ Corresponding author.
} 
with $\mathrm{CD}$ is a known but very rare condition especially in children. Invagination may be the presenting symptom of $\mathrm{CD}$ and moreover, CD patients with recurrent invaginations have been also reported [4] [5].

Herein, we will discuss three children with diagnosis of celiac disease who presented with invagination and intestinal pseudo-obstruction.

By this way we aimed to increase the awareness of clinicians about togetherness of these conditions.

\section{Case Reports}

\subsection{Case 1}

A nine-year-old boy was admitted to the hospital with abdominal pain and bilious vomiting for three days. His vital signs were normal. His weight was $20 \mathrm{~kg}\left(<5^{\text {th }}\right.$ percentile) and height was $124 \mathrm{~cm}\left(10^{\text {th }}\right.$ percentile). In physical examination, abdominal distention and diffuse tenderness on palpation were detected. Moreover, a mass lesion on the left lower quadrant was palpated. Laboratory test results were as follows: hemoglobin (Hgb), $9 \mathrm{~g} / \mathrm{dl}\left(14\right.$ - 18); white blood count (WBC) , $22 \times 10^{3} / \mathrm{uL}$ (4.5 - 11), C-reactive protein (CRP), $4.8 \mathrm{mg} / \mathrm{dL}(0$ - 5), and $\mathrm{Na} 128 \mathrm{mmol} / \mathrm{L}(134-145)$. There was free air under the diaphragm in standing direct abdominal graph (SDAG) together with multiple air-fluid levels (Figure 1). Abdominal computed tomography (CT) revealed an

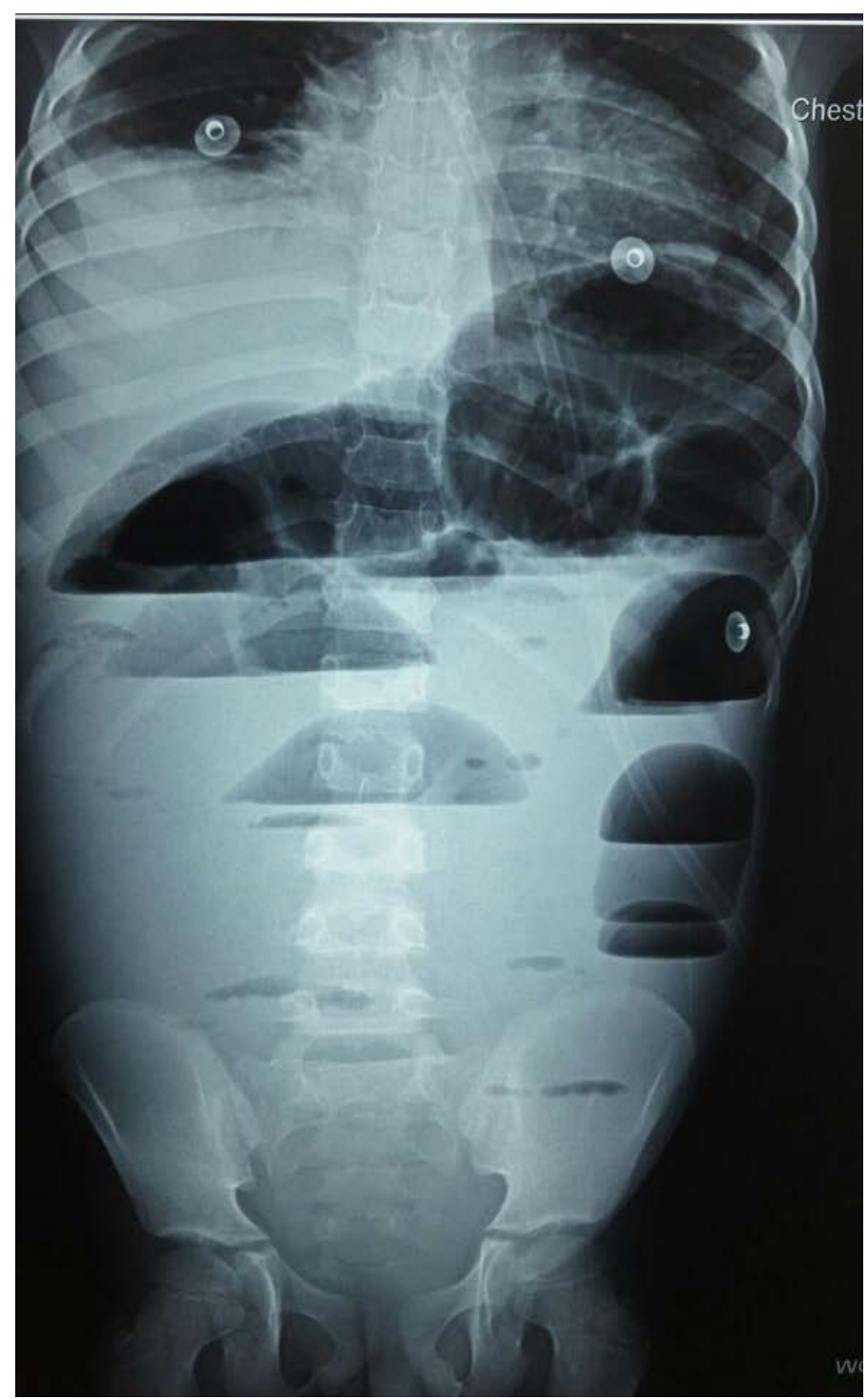

Figure 1. Free air under the diaphragm and multiple air-fluid levels in standing direct abdominal graph. 
ileo-ileal invagination of $5.8 \mathrm{~cm}$ in length in the left lower quadrant, minimal free fluid between intestinal loops, an extensive dilatation between colonic segments (Figure 2) and fluid accumulation in Douglas pouch. Due to the presence of signs of perforation, laparotomy was performed. Since intestinal necrosis was found in ileo-ileal invaginated segment, about $40 \mathrm{~cm}$ proximal to the cecum (Figure 3) partial ileal resection compromising perforation and primary end to end anastomosis were performed. Laparotomy, did not reveal any other intestinal pathology or enlarged lymph nodes. After operation appropriate fluid and electrolyte replacement was ordered. However, on postoperative 8th day, abdominal distention was still presenttogether with air-fluid levels in SDAG and the patient was consulted with pediatric gastroenterology department. Pediatric gastroenterologists obtained multiple biopsies from duodenum. The histopathology of biopsy specimens were reported as focal villus atrophy, intraepithelial lymphocytosis and hyperplasia and mitosis in crypts (Figure 4). His serum anti-tissue transglutaminase antibody (tTG-Ab) immunoglobulin (Ig) G level was $172 \mathrm{U} / \mathrm{mL}$ (normal range < 20) and antigliadin IgA level was $136 \mathrm{mg} / \mathrm{dL}$ (AGA) (normal range < 20). (IMMCODiagnostics, Inc., Buffalo, NY). With approximately 1 year of gluten free diet (GFD), the patient gained $8 \mathrm{~kg}$, and histopathology of terminal ileum biopsy was unremarkable. With in 24 months of follow-up after operation, signs of intestinal obstruction or abdominal fluid accumulation were not present on abdominal CT.

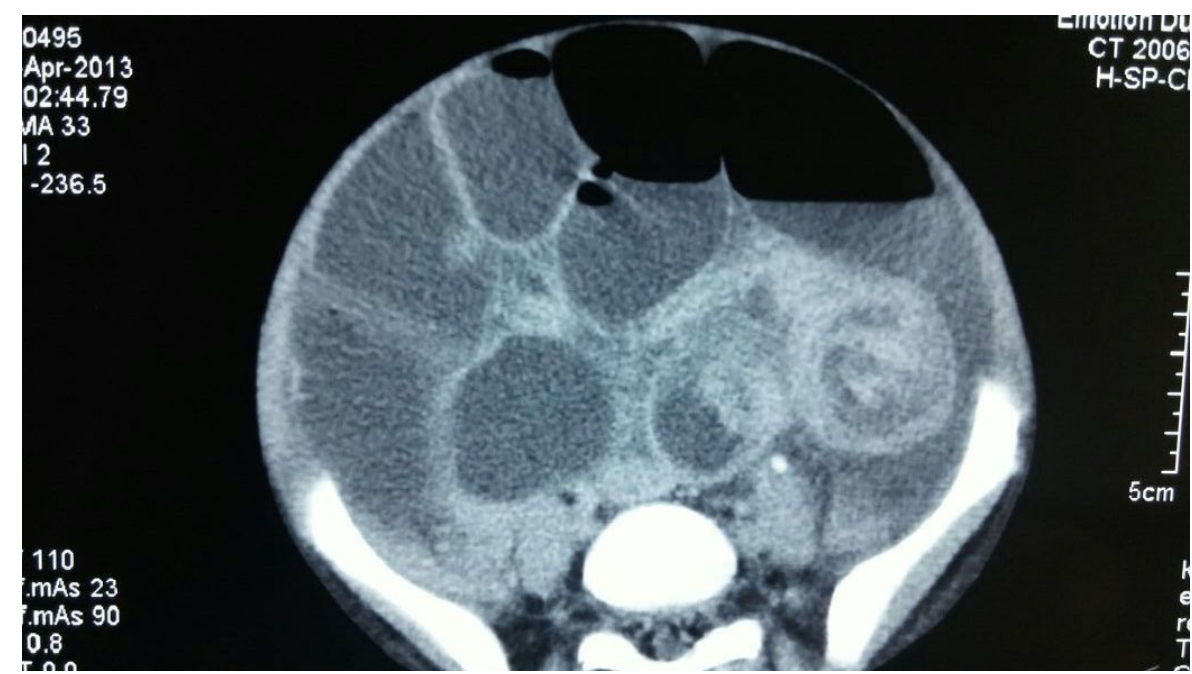

Figure 2. Abdominal computed tomography: an ileo-ileal invagination and an extensive dilatation between colonic segments.

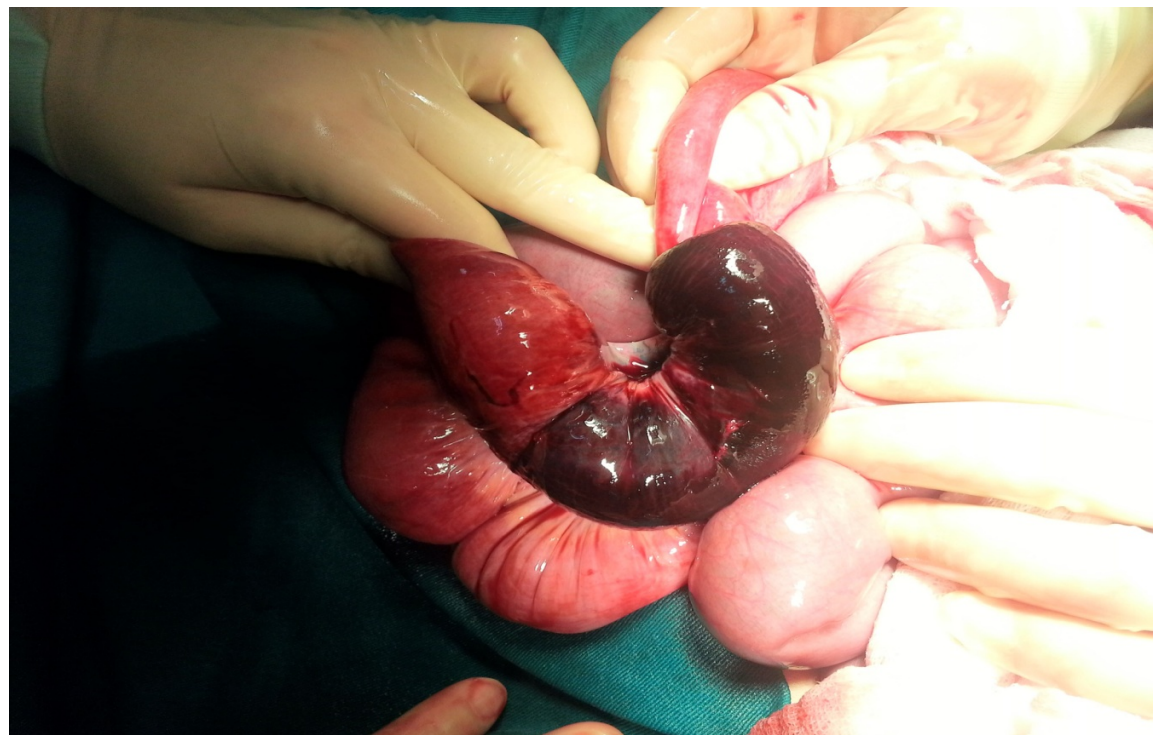

Figure 3. Intestinal necrosis present in ileo-ileal invaginated segment. 


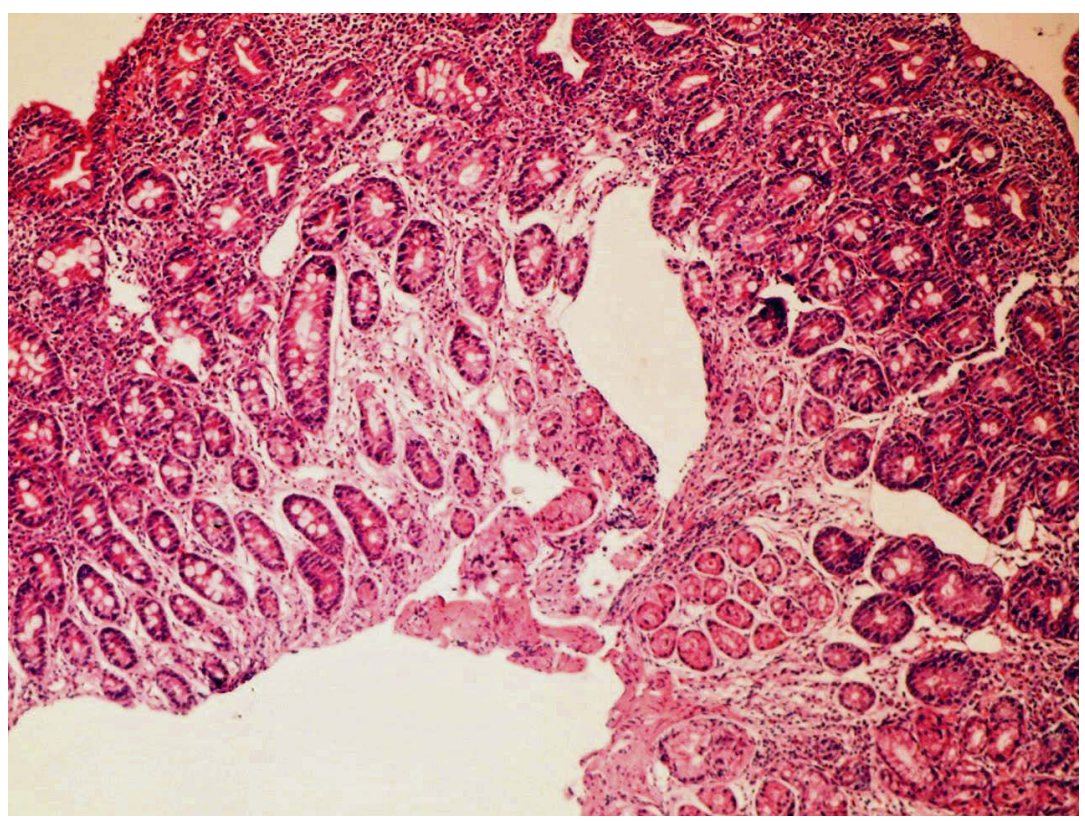

Figure 4. Total villous atrophy,intraepithelial lymphcytosis, cyrpt hyperplasia (marshoberhauber, stage 3c), HE, X40.

\subsection{Case 2}

A six-year-old girl was admitted to the hospital with colic type abdominal pain and recurrent diarrhea. These self-limited episodes were lasting about one week. She was cachectic in appearance with a history of anorexia. Her weight was $17 \mathrm{~kg}\left(10^{\text {th }}-25^{\text {th }}\right.$ percentile) and her height was $110 \mathrm{~cm}$ (25 percentile). Her abdomen was distended without any tenderness on palpation. Laboratory test results were as follows: Hemoglobin, $10.2 \mathrm{~g} / \mathrm{dl}$ (14 18); WBC, $13.5 \times 10^{3} / \mathrm{uL}(4.5$ - 11), CRP, 10 (0 - 5) mg/dL, and Na $132 \mathrm{mmol} / \mathrm{L}$ (135 - 145). There were multiple fluid-air levels in SDAG. In abdominal ultrasound, distention in intestinal loops, and a reductable, transient ileo-ileal donut-shaped invagination with a $4 \mathrm{~cm}$ diameter was present in right upper quadrant. Control sonograms obtained after reduction of invagination were unremarkable. Her serum tTG IgG, and tTG IgA levels were $87 \mathrm{U} / \mathrm{ml}$, and $100 \mathrm{U} / \mathrm{ml}$., respectively. Endoscopic duodenal biopsy results revealed celiac disease with Marsh III histopathological appearance-intraepithelial lymphocytosis. With GFD, the asymptomatic patient gained $7 \mathrm{~kg}$ of weight within 1 year.

\subsection{Case 3}

A ten-year-old boy was admitted to the hospital with abdominal pain, constipation, vomiting and distention for 6 months. It was learnt that he had ileus attacks, and the last attack was 2 months ago which did not require surgical interventions. In physical examination, abdomen was distended with diffuse tenderness on palpation. In auscultation, the abdominal sounds were hyperactive. His Hgb level was $9.8 \mathrm{~g} / \mathrm{dl}$ and CRP, erythrocyte sedimentation rate and electrolyte levels were within normal limits . His serum tTG IgG, andtTG IgA levels were 56 U/ $\mathrm{ml}$, and $68 \mathrm{U} / \mathrm{ml}$, respectively. There was an air fluid level in abdominal X-ray as a sign of intestinal obstruction (Figure 5). In abdominal ultrasound signs of invagination were not present but intestinal loops were dilated. Endoscopic duodenal biopsy results confirmed the diagnosis of CD (Figure 6). Nasogastric tube was inserted and fluid and antibiotic treatments were ordered. There was a bilious drainage from nasogastric tube. On the $3^{\text {rd }}$ day of his hospitalization, his clinical picture improved and with an insertion of rectal tube, his symptoms reduced. After decompression, SDAG and contrast enhanced colon graphs were normal. With three months of GFD, he gained two kg.

\section{Discussion}

We have presented three children admitted to the hospital with the invagination symptoms and concomitant diagnosis of $\mathrm{CD}$. Invagination is the prolabation of a part of intestinal loops into the lumen of the adjacent segment. 


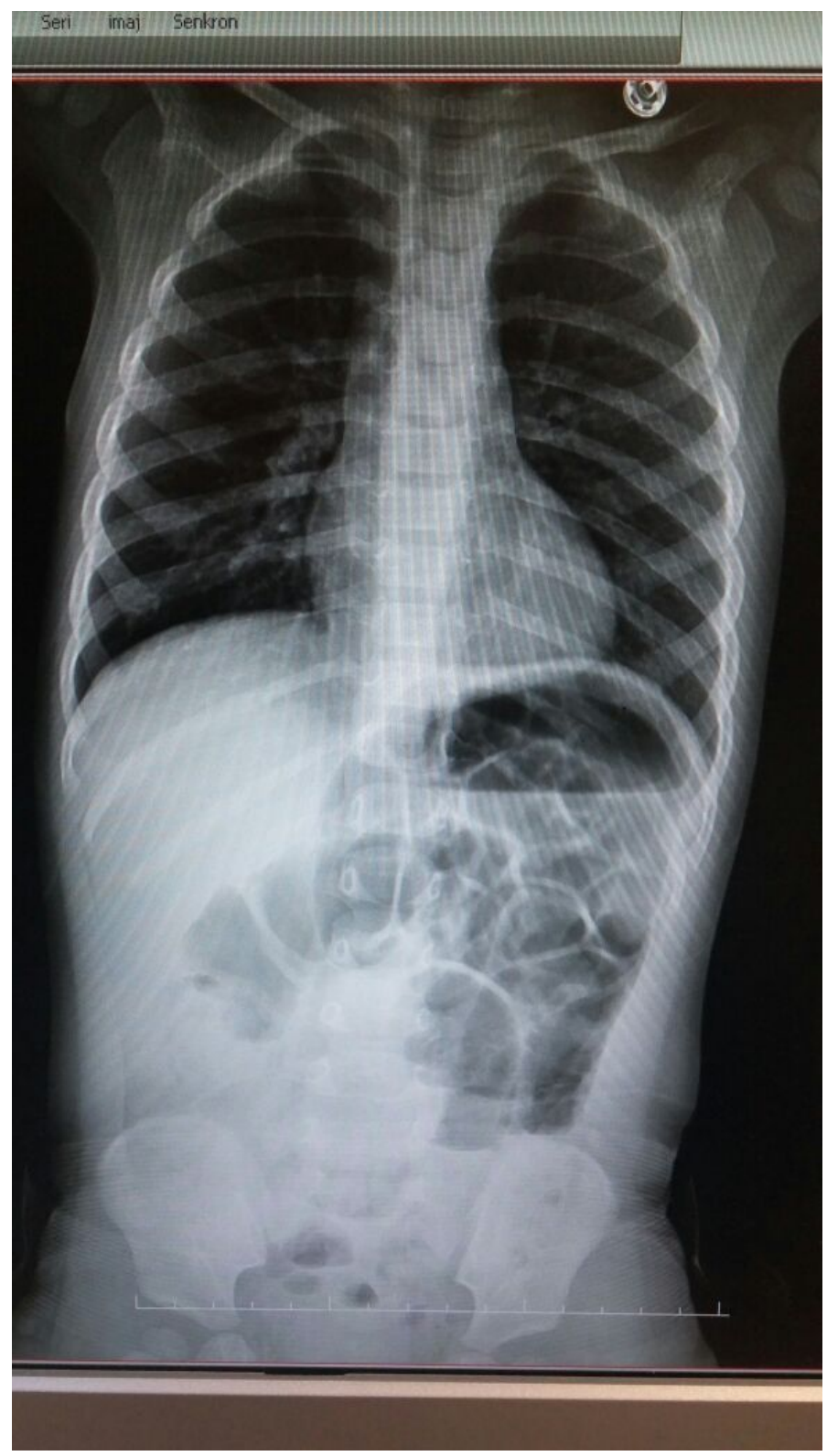

Figure 5. An air fluid level in abdominal X-ray as a sign of intestinal obstruction.

It is generally an idiopathic condition reported more commonly in children [1]. About $90 \%$ of the cases with invagination are between six months and two years of age. However, all three cases of us were older than six years of age. Its symptoms include pain, nausea-vomiting and rectal bleeding. Conservative treatment under ultrasound is the preferred method in transient small intestinal invaginations, however, in patients with persistent invagination, atypical radiological findings or deteriorating clinical situation may require prompt surgical exploration [1]. Our $2^{\text {nd }}$ and $3^{\text {rd }}$ cases were followed with conservative treatment, but the first one was operated due to the presence of the signs of perforation.

Gluten sensitive enteropathy, $C D$, is an autoimmune reaction to the gliadin fraction of gluten present in cereals as barley, rye and wheat [6]. The disease presents with villous atrophy and crypt hyperplasia after ingestion of gluten [3]. It is reported in $1 \%-2 \%$ of general population [7]. The typical symptoms of CD include chronic diarrhea, anemia and growth retardation. In all 3 cases reported here, growth retardation and anemia were present.

On the other hand, CD patients may present with atypical symptoms such as infertility, abdominal distention 


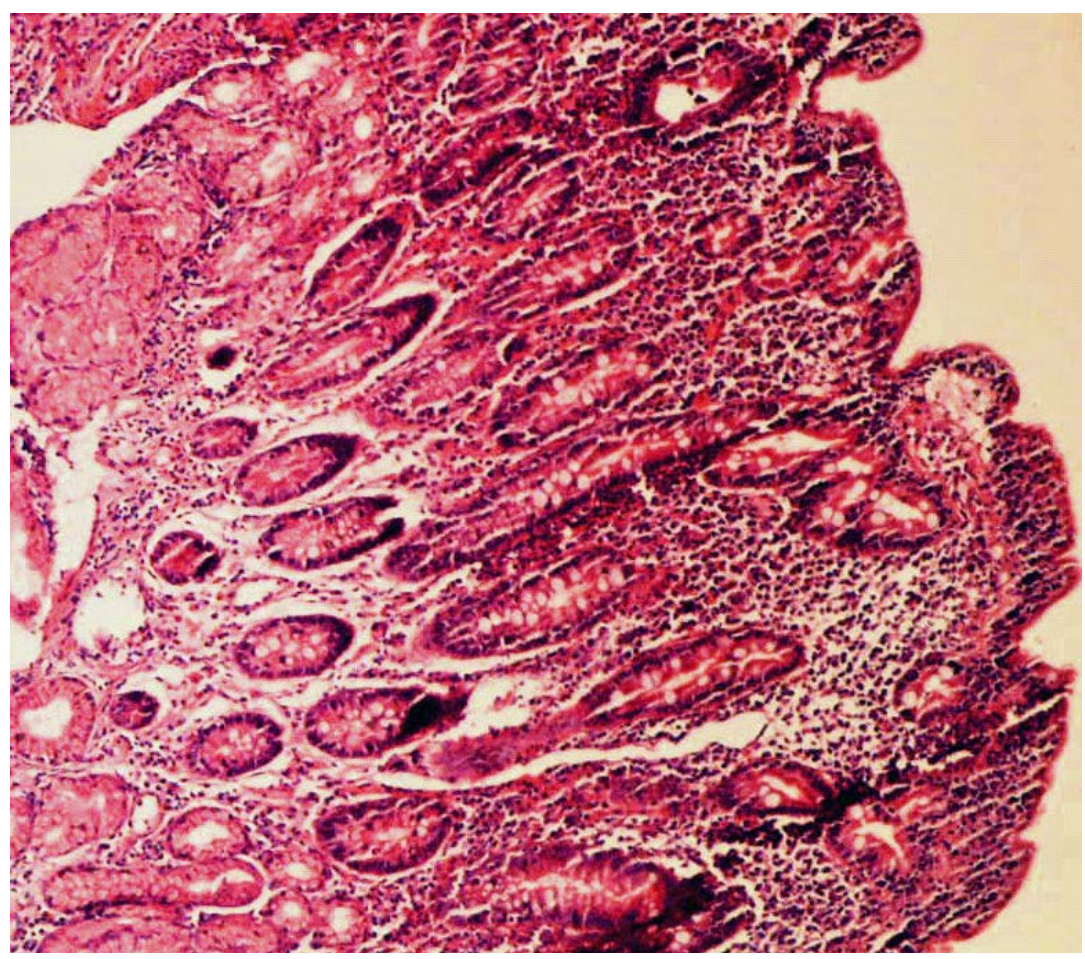

Figure 6. Total villous atrophy,intraepithelial lymphcytosis,cyrpt hyperplasi, HE, X100.

or constipation. The prevalence of acute abdominal pain in CD patients is 3\% and chronic or recurrent abdominal pain may also be the presenting symptom of CD [8]. Although the exact cause of abdominal pain in CD is unknown, autonomic dysfunction in intestinal structures, hypotonic small intestine loops, and deteriorations in neural control of intestinal movements, increase in the thickness of small intestine wall, diffuse inflammation, dilatations in intestinal loops, and excessive peristaltism reported in CD patients may predispose to the development of invagination. Delayed small intestinal transit time and decrease in motility are also accused. Especially in our first case, persistence of abdominal distention made us search for the presence of CD.

The invagination prevalence among CD patients was reported as 1.2 - 18 percent. Hizal et al. reported that transient invagination may accompany 20\% of CD patients and Reilly et al. reported that in children with CD risk of invagination increased 10 - 20 times [4] [5]. Similarly, Cornelius et al. suggested checking for CD in patients with invagination though they were asymptomatic [9]. Moreover, Gonda et al reported that invagination and abdominal pain may be the presenting symptom in as high as $57 \%$ of the patients with CD and additionally in patients with recurrent invagination on Gluten Free Diet (GFD) any recurrence was not determined [10]. Similarly, recurrence was not observed in our cases after GFD.

In conclusion, children with pseudo-obstruction and invagination without an underlying etiology should be evaluated for the presence of CD especially if they have accompanying growth retardation or anemia and if they are at an unusual age for invagination. Further studies are warranted to elucidate the exact relationship of invagination with CD.

Written informed consent was obtained from the patients's legal guardians for publication of this case report and any accompanying images. A copy of the written consent is available for review by the Editor-in-Chief of this journal.

\section{Competing Interests Section}

The authors declare that they have no competing interests

\section{Author's Contribution Section}

Sevgi Buyukbese Sarsu designed the study and acquired the data; drafted the article and revised it critically for 
important intellectual content. Mustafa Demirci made radiologic examination.

\section{References}

[1] Kennedy, M. and Liacouras, C.A. (2011) Intussusception. In: Kliegman, R.M., Nelson, W.E., Eds., Nelson Textbook of Pediatrics, 19th Edition, Elsevier Saunders, Philadelphia, 1087-1089.

[2] Lappalainen, S., Ylitalo, S., Arola, A., Halkosalo, A., Räsänen, S. and Vesikari, T. (2012) Simultaneous Presence of Human Herpesvirus 6 and Adenovirus Infections in Intestinal Intussusception of Young Children. Acta Paediatrica, 101, 663-670. http://dx.doi.org/10.1111/j.1651-2227.2012.02616.x

[3] Paul, S.P., Kirkham, E.N., Pidgeon, S. and Sandmann, S. (2015) Coeliac Disease in Children. Nursing Standard, 29, 36-41.

[4] Reilly, N.R., Aguilar, K.M. and Green, P.H. (2013) Should Intussusception in Children Prompts Screening for Celiac Disease? Journal of Pediatric Gastroenterology and Nutrition, 56, 56-59. http://dx.doi.org/10.1097/MPG.0b013e31826a1099

[5] Hizal, G., Gürakan, F., Balamtekın, N. and Uslu Kizilkan, N. (2012) Celiac Disease Presenting with Intestinal Obstruction: Report of Two Cases. The Turkish Journal of Gastroenterology, 23, 416-417.

[6] Grados, A., Bernard, F., Coquet-Reinier, B., Rossi, P., Bagneres, D., Demoux, A.L., et al. (2011) Acute Bowel Intussusception Revealing Celiac Disease: A New Case and Literature Review. La Revue de Médecine Interne, 32, 628-632. http://dx.doi.org/10.1016/j.revmed.2011.03.334

[7] Walker, M.M., Murray, J.A., Ronkainen, J., Aro, P., Storskrubb, T., D’Amato, M., Lahr, B., Talley, N.J. and Agreus, L. (2010) Detection of Celiac Disease and Lymphocytic Enteropathy by Parallel Serology and Histopathology in a PopulationBased Study. Gastroenterology, 139, 112-119. http://dx.doi.org/10.1053/j.gastro.2010.04.007

[8] Reilly, N.R., Aguilar, K., Hassid, B.G., et al. (2011) Celiac Disease in Children with Normal Weight and Overweight: Clinical Features and Growth Outcomes Following a Gluten-Free Diet. Journal of Pediatric Gastroenterology and Nutrition, 53, 528-531. http://dx.doi.org/10.1097/mpg.0b013e3182276d5e

[9] Cornelius Van Niel, W. (2013) Is Intussusception a Marker for Celiac Disease in Children? Journal of Pediatric Gastroenterology and Nutrition.

[10] Gonda, T.A., Khan, S.U., Cheng, J., Lewis, S.K., Rubin, M. and Green, P.H. (2010) Association of Intussusception and Celiac Disease in Adults. Digestive Diseases and Sciences, 55, 2899-903. http://dx.doi.org/10.1007/s10620-009-1086-8 